\title{
Wpływ nieklasycznych czynników ryzyka sercowo-naczyniowego na wybór terapii hipolipemizującej i hipotensyjnej
}

\author{
Influence of non-classical cardiovascular risk factors \\ on the choice of hypotensive and lipid-lowering therapy
}

\author{
Anna Ryś ${ }^{1}$, Karolina Semczuk ${ }^{1}$, Bartosz Krzowski ${ }^{1}$, Anna E. Płatek ${ }^{1,2}$, Filip M. Szymański ${ }^{1}$ \\ ${ }^{1}$ K Katedra i Klinika Kardiologii Warszawskiego Uniwersytetu Medycznego \\ ${ }^{2}$ Katedra i Zakład Patologii Ogólnej i Doświadczalnej Warszawskiego Uniwersytetu Medycznego
}

\section{Streszczenie}

Ocena ryzyka sercowo-naczyniowego w codziennej praktyce klinicznej jest niezwykle istotna. Wpływa ona na sposób sercowo-naczyniowego leczenia wielu pacjentów z chorobami układu sercowo-naczyniowego. Zalecane narzędzia, takie jakie jak POL-SCORE, nie uwzględniają całego obrazu klinicznego wszystkich chorych.

Opisany przypadek kliniczny ukazuje, jak zastosowanie nieklasycznych czynników ryzyka w praktyce klinicznej, zmienia przyjęty dotąd schemat postępowania.

Słowa kluczowe: ryzyko sercowo-naczyniowe, nadciśnienie tętnicze, dyslipidemia

Folia Cardiologica 2017; 12, supl. B: B5-B8

\section{Wstęp}

Ocena ryzyka sercowo-naczyniowego stanowi obecnie podstawę w podejmowaniu decyzji dotyczących czasu i sposobu inicjacji leczenia hipolipemizującego oraz hipotensyjnego. W obowiązujących obecnie wytycznych towarzystw naukowych $[1,2]$ zaleca się, aby sposób leczenia był w każdym wypadku oparty na kompleksowej ocenie ryzyka sercowo-naczyniowego chorych. Nierzadko jednak w powszechnie używanych skalach oceny możliwości wystąpienia w przyszłości incydentów sercowo-naczyniowych lub zgonu z ich przyczyny ryzyko związane z występowaniem nieklasycznych czynników ryzyka sercowo-naczyniowego, na jakie narażeni są pacjenci ze względu na współczesny tryb życia oraz rozwój cywilizacyjny, pozostaje niedoszacowane.

\section{Opis przypadku}

Mężczyzna w wieku 55 lat, zawodowy kierowca, zgłosił się do kardiologa po rutynowych badaniach okresowych wykonanych w pracy. Pacjent od ponad 30 lat pracuje w dużym polskim mieście w systemie pracy zmianowej jako kierowca autobusu komunikacji publicznej. W czasie wizyty u lekarza zakładowego wartości ciśnienia tętniczego pacjenta wyniosły 165/95 mm Hg. Pacjent, zaniepokojony podwyższonymi wartościami ciśnienia, zaczął nieregularnie wykonywać pomiary domowe, a po namowach żony zgłosił się do kardiologa.

Z zapisków wykonanych przez chorego wynikało, że wartości jego pomiarów w warunkach dobowych wynosiły około 145/95 mm Hg, niemniej jednak pomiary nie były wykonywane systematycznie i nie pozwalały na rzetelna ocenę wartości ciśnienia tętniczego. Podczas pierwszej wizyty wykonano kolejny pomiar wartości ciśnienia tętniczego, który wyniósł 152/94 mm Hg. Po zebraniu wywiadu okazało się, że jedynym klasycznym czynnikiem ryzyka sercowo-naczyniowego, który występował u pacjenta (poza płcią męską), był dodatni wywiad w kierunku chorób układu sercowo-naczyniowego w rodzinie. Pacjent przyznał się także, że jest obecnie w trakcie leczenia stoma-

Adres do korespondencji: lek. Anna Ryś, I Katedra i Klinika Kardiologii, Warszawski Uniwersytet Medyczny, ul. Banacha 1a, 02-097 Warszawa, tel. 225992655 , e-mail: aniarys30@gmail.com 
tologicznego z powodu zawansowanej próchnicy zębów oraz choroby przyzębia. Mężczyźnie zalecono wykonanie badania elektrokardiograficznego oraz badań laboratoryjnych i kolejną wizytę po około 4 tygodniach. Podczas kolejnej wizyty pomiar wartości ciśnienia tętniczego wyniósł 146/88 mm Hg. Średnia z dwóch wizyt wyniosła zatem 149/91 mm Hg, co zgodnie z obowiązującymi obecnie zaleceniami nakazywało potwierdzenie rozpoznania nadciśnienia tętniczego w badaniu 24-godzinnego monitorowania wartości ciśnienia tętniczego (ABPM, ambulatory blood pressure monitoring). Natomiast w wynikach badań laboratoryjnych nie odnotowano istotnych nieprawidłowości poza podwyższonymi stężeniami cholesterolu, które wynosiły $190 \mathrm{mg} / \mathrm{dl}$ w przypadku cholesterolu całkowitego oraz $116 \mathrm{mg} / \mathrm{dl}$ w przypadku cholesterolu frakcji LDL (low-density lipoprotein). Pacjenta poddano ABPM, w którym podczas interpretacji wyników następnego dnia potwierdzono nadciśnienie tętnicze; średnie dobowe wartości ciśnienia tętniczego wynosiły 144/96 mm Hg (w czasie czuwania 154/99 mm Hg, w czasie snu 138/88 mm Hg), z zachowanym prawidłowym spadkiem w godzinach nocnych.

Aby ocenić ryzyko sercowo-naczyniowe u pacjenta, zdecydowano się skorzystać z dwóch skal - skali POL-SCORE oraz tabeli zawartej w wytycznych Polskiego Towarzystwa Nadciśnienia Tętniczego [2, 3] (ryc. 1A, B).

Na podstawie obu skal ryzyka ryzyko sercowo-naczyniowe pacjenta oszacowano jako umiarkowane i równe 4\% w polskiej modyfikacji skali SCORE.

Zgodnie z obowiązującymi obecnie wytycznymi u osób z tej grupy ryzyka przy wartościach ciśnienia tętniczego zaobserwowanych u opisywanego pacjenta należy najpierw podjąć próbę zmodyfikowania stylu życia, a następnie - jeśli okaże się to nieskuteczne - po 3 miesiącach rozpocząć farmakoterapię. Wydaje się jednak, że w takim postępowaniu nie uwzględnia się całościowego profilu ryzyka chorego i dlatego w każdym przypadku może ono być właściwe. W rzeczywistości u opisywanego pacjenta występowało znacznie więcej czynników ryzyka, które nie są brane pod uwagę w klasycznej ocenie:

- pacjent był kierowcą zawodowym, przez co narażony był na stres, nieregularne godziny pracy (również w nocy), małą aktywność fizyczną;

- zdiagnozowano u niego chorobę przyzębia, która między innymi w związku z toczącym się procesem zapalnym powoduje wzrost ryzyka chorób serca (ryc. 2);

- mieszkał i pracował w centrum dużego miasta, w którym był nieustannie narażony na zanieczyszczenie powietrza (ryc. 3).

W związku z tym realne ryzyko chorób serca u omawianego pacjenta było istotnie wyższe niż to, które oszacowano w skalach oceny. W związku z tym pacjentowi zalecono modyfikację stylu życia, ale także włączenie terapii hipolipemizującej i hipotensyjnej podczas pierwszej wizyty lekar- skiej. Zalecono zastosowanie walsartanu w dawce $160 \mathrm{mg} /$ dobę oraz rosuwastatyny w dawce $20 \mathrm{mg} /$ dobę. Pacjentowi zalecono wykonanie badań kontrolnych stężenia cholesterolu oraz wizyte kontrolną za 4 tygodnie. U omawianego pacjenta, zgodnie z klasycznym sposobem oceny ryzyka, docelowe stężenia cholesterolu frakcji LDL powinny wynosić mniej niż 115 mg/dl, jednak uwzględnienie nowych czynników ryzyka spowodowało przeniesienie pacjenta do grupy o wysokim ryzyku sercowo-naczyniowym, w której - w zgodzie za obecnymi wytycznymi [1] - zasadne jest obniżanie stężenia cholesterolu frakcji LDL do poniżej 100 mg/dl lub zmniejszenie o co najmniej 50\%, jeśli wyjściowo wynosi ono między 100 mg/dl i 200 mg/dl. Dlatego, mając na uwadze poprawę rokowania pacjenta, zdecydowano o zastosowaniu rosuwastatyny w dawce $20 \mathrm{mg}$.

Podczas wizyty kontrolnej zaobserwowano, że wartości ciśnienia tętniczego zmniejszyły się do 132/78 mm Hg, a stężenie cholesterolu frakcji LDL wyniosło $74 \mathrm{mg} / \mathrm{dl}$. Leczenie było dobrze tolerowane przez pacjenta, nie odczuwał on żadnych skutków ubocznych terapii. W związku z tym oraz ze względu na fakt, że nowoczesne statyny, takie jak rosuwastatyna, nie muszą być przyjmowane wieczorem, zdecydowano się zamienić oba stosowane leki na preparat złożony zawierający walsartan i rosuwastatynę w jednej tabletce, którą podawano rano, aby ułatwić pacjentowi przestrzeganie zaleceń. Pozwoliło to prawdopodobnie istotnie obniżyć ryzyko zgonu tego pacjenta spowodowane chorobami układu sercowo-naczyniowego.

\section{Dyskusja}

W codziennej praktyce klinicznej skale oceny ryzyka bardzo ułatwiają pracę lekarzom i często są podstawą do podejmowania decyzji o rozpoczynaniu i sposobie leczenia pacjentów. Niemniej jednak wiele nowych nieklasycznych czynników ryzyka sercowo-naczyniowego nie jest w tych skalach ujętych, co sprawia, że duży odsetek pacjentów nie jest dostatecznie oszacowany.

Do nowo ocenianych czynników ryzyka sercowo-naczyniowego zaliczane są między innymi obecne u omawianego chorego: choroby przyzębia, narażenie na stres i niekorzystne czynniki fizykochemiczne w pracy zawodowej oraz narażenie na zanieczyszczenie powietrza. Kierowcy zawodowi, tak jak omawiany chory, to grupa, w której nieklasyczne czynniki ryzyka występują bardzo często [4]. Co więcej, nie tylko ze względu na pracę zawodową, ale także miejsce zamieszkania są oni narażeni zanieczyszczenie powietrza.

O zanieczyszczeniu powietrza mówi się ostatnio bardzo wiele szczególnie w kontekście medialnie nagłośnionego problemu smogu w dużych miastach Polski. Jednak już od wielu lat było ono uznawane za ważny czynnik ryzyka i marker zagrożenia rozwojem miażdżycy i chorób będących jej konsekwencjami [5]. 


\begin{tabular}{|l|c|c|c|c|}
\hline \multirow{2}{*}{ A Sytuacja kliniczna } & \multicolumn{4}{c|}{ Ciśnienie tętnicze [mm Hg] } \\
\cline { 2 - 5 } & $\begin{array}{c}\text { Wysokie prawidłowe } \\
\text { SBP 130-139 } \\
\text { lub DBP 85-99 }\end{array}$ & $\begin{array}{r}\text { NT 1. stopnia } \\
\text { SBP 140-159 } \\
\text { lub DBP 90-99 }\end{array}$ & $\begin{array}{r}\text { NT 2. stopnia } \\
\text { SBP 160-179 } \\
\text { lub DBP 100-109 }\end{array}$ & $\begin{array}{c}\text { NT 3. stopnia } \\
\text { SBP } \geq 180 \\
\text { lub DBP } \geq 110\end{array}$ \\
\hline Brak czynników ryzyka & Przeciętne & Niskie & Umiarkowane & Wysokie \\
\hline 1-2 czynniki ryzyka & Niskie & Umiarkowane & Umiarkowane & Wysokie \\
\hline$\geq 3$ czynników ryzyka & Umiarkowane & Umiarkowane & Wysokie & Wysokie \\
\hline $\begin{array}{l}\text { Powikłania narządowe, } \\
\text { CKD w 3. stadium, } \\
\text { cukrzyca }\end{array}$ & Wysokie & Wysokie & Wysokie & Bardzo wysokie \\
\hline $\begin{array}{l}\text { Jawna CVD, CKD w } \geq 4 . \\
\text { stadium }\end{array}$ & Bardzo wysokie & Bardzo wysokie & Bardzo wysokie & Bardzo wysokie \\
\hline
\end{tabular}

\section{B}

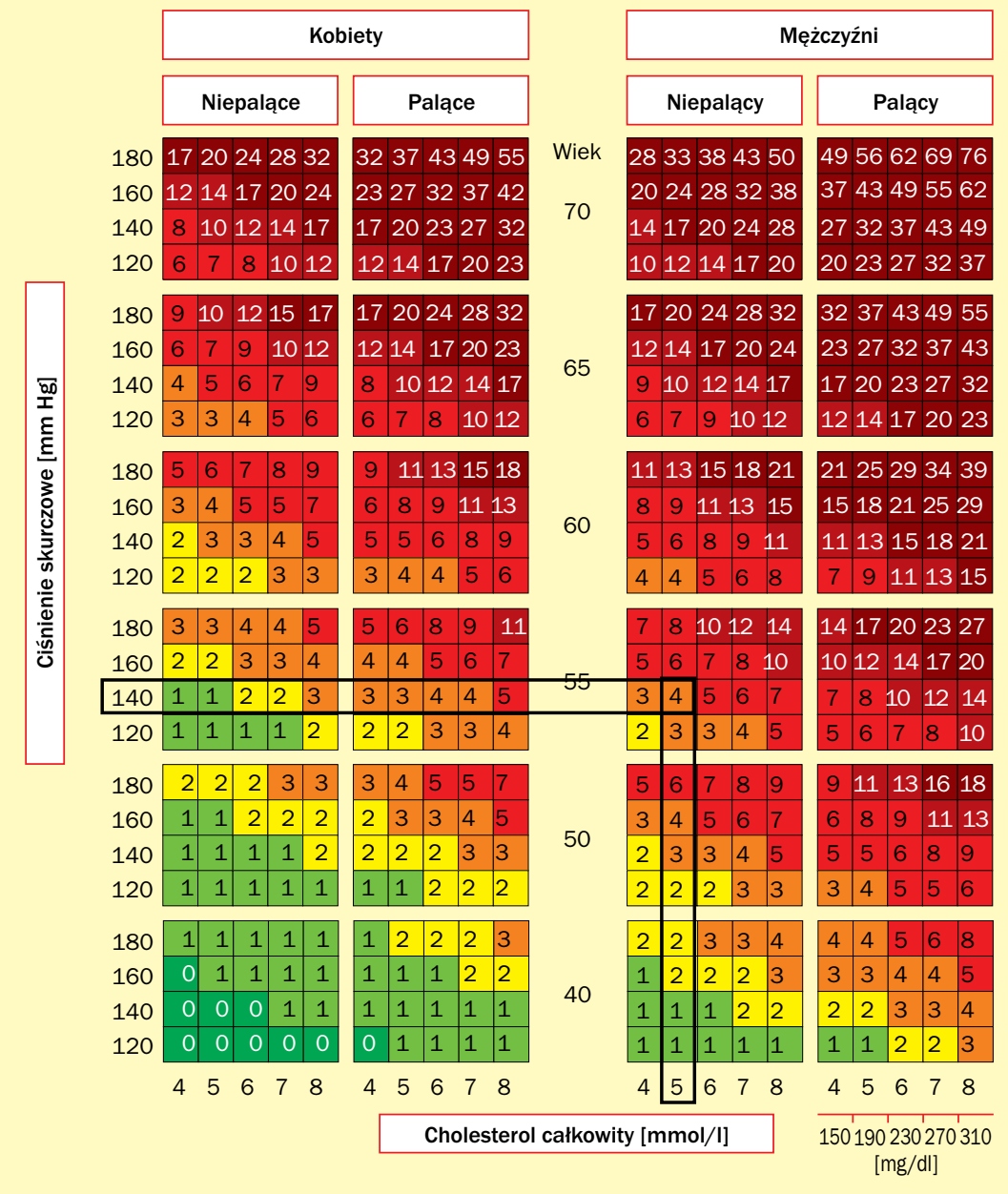

Rycina 1A, B. Ocena ryzyka sercowo-naczyniowego pacjenta; SBP (systolic blood pressure) - skurczowe ciśnienie tętnicze; DBP (diastolic blood pressure) - rozkurczowe ciśnienie tętnicze; CKD (chronic kidney disease) - przewlekła choroba nerek; CVD (cardiovascular disease) - choroba układu sercowo-naczyniowego (źródła [2, 3]) 


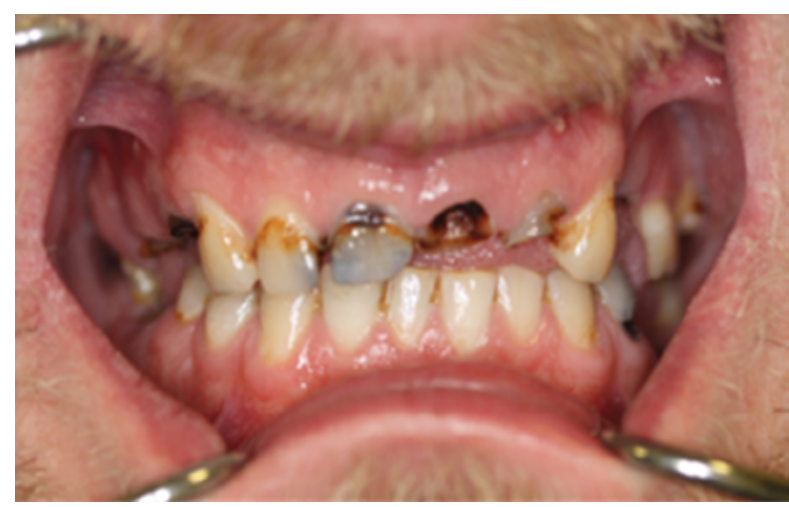

Rycina 2. Jama ustna pacjenta

Stratyfikacja ryzyka sercowo-naczyniowego stanowi podstawę pracy lekarza praktyka. Zalecane narzędzia, takie jakie jak POL-SCORE, nie uwzględniają całego obrazu klinicznego wszystkich chorych. Włączenie do rutynowej

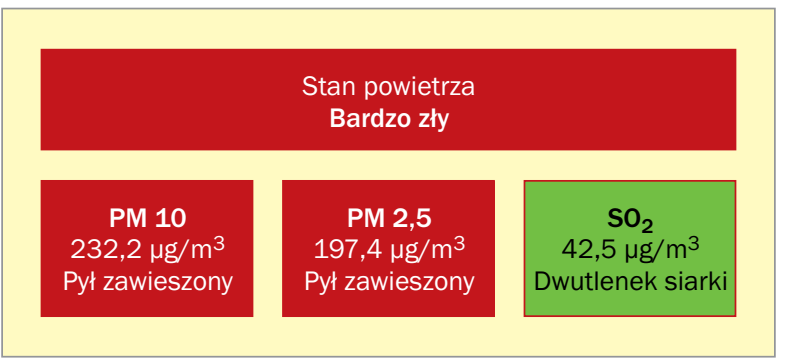

Rycina 3. Dane dotyczące zanieczyszczenia powietrza w rejonie zamieszkania pacjenta

oceny pacjentów tych czynników ryzyka, a także na przykład chorób przyzębia, może się w istotny sposób przyczynić do poprawy rokowania chorych. Z kolei zastosowanie podczas leczenia preparatów złożonych może pomóc kontynuować tę prawidłowo rozpoczętą terapię.

\section{Abstract}

Cardiovascular risk assessment in clinical practice isessential. It affects treatment methods of cardiovascular diseases in patients. Recommended tools such as POL-SCORE do not take into account the clinical picture of all the patients. The clinical case shows that the use of nonclassical elements of risk factors in clinical practice changes the scheme of action undertaken so far.

Key words: cardiovascular risk, hypertension, dyslipidemia

Folia Cardiologica 2017; 12, supl. B: B5-B8

\section{Piśmiennictwo}

1. Piepoli MF, Hoes AW, Agewall S, et al. Authors/Task Force Members. 2016 European Guidelines on cardiovascular disease prevention in clinical practice: The Sixth Joint Task Force of the European Society of Cardiology and Other Societies on Cardiovascular Disease Prevention in Clinical Practice (constituted by representatives of 10 societies and by invited experts)Developed with the special contribution of the European Association for Cardiovascular Prevention \& Rehabilitation (EACPR). Eur Heart J. 2016; 37(29): 2315-2381, doi: 10.1093/eurheartj/ehw106, indexed in Pubmed: 27222591.

2. Tykarski A, Narkiewicz K, Gaciong Z. Zasady postępowania w nadciśnieniu tętniczym - 2015 rok. Wytyczne Polskiego Towarzystwa Nadciśnienia Tętniczego. Arterial Hypertens. 2015; 19: 53-58.
3. Zdrojewski T, Jankowski P, Bandosz P, et al. [A new version of cardiovascular risk assessment system and risk charts calibrated for Polish population]. Kardiol Pol. 2015; 73(10): 958-961, doi: 10.5603/ KP.2015.0182, indexed in Pubmed: 26521843.

4. Platek AE, Szymanski FM, Filipiak KJ, et al. Prevalence of depressive disorders in professional drivers - epidemiologic subanalysis of the RACER study. Psychiatr Pol. 2016; 50(4): 859-871, doi: 10.12740/ PP/44395, indexed in Pubmed: 27847934.

5. Niiranen TJ, Vasan RS. Epidemiology of cardiovascular disease: recent novel outlooks on risk factors and clinical approaches. Expert Rev Cardiovasc Ther. 2016; 14(7): 855-869, doi: 10.1080/14779072.2 016.1176528, indexed in Pubmed: 27057779. 